Kroneman, M., Verheij, R., Tacken, M., Zee, J. van der. Urban-rural health differences: primary care data and self reported data render different results. Health and Place: 2010, 16(5), 893-902

\begin{tabular}{|l|l|}
\hline $\begin{array}{l}\text { Postprint } \\
\text { Version }\end{array}$ & 1.0 \\
\hline Journal website & $\underline{\text { http://dx.doi.org/10.1016/j.healthplace.2010.04.015 }}$ \\
\hline Pubmed link & $\underline{\text { http://www.ncbi.nlm.nih.gov/pubmed/20493756 }}$ \\
\hline DOI & $10.1016 /$ j.healthplace.2010.04.015 \\
\hline
\end{tabular}

This is a NIVEL certified Post Print, more info at http://www.nivel.eu

\title{
Urban-rural health differences: primary care data and self reported data render different results
}

\author{
MADELON KRONEMAN ${ }^{A,}$, ROBERT VERHEIJ ${ }^{A}$, MARGOT TACKEN ${ }^{B}$ AND JOUKE VAN DER ZEE ${ }^{A, C}$ \\ ${ }^{a}$ NIVEL, Netherlands Institute of Health Services Research, P.O. Box 1568, 3500 BN Utrecht, The \\ Netherlands \\ ${ }^{b}$ IQ healthcare, Scientific Institute for Quality of Healthcare, Radboud University Nijmegen Medical Centre, \\ P.O. Box 9101, 6500 HB, Nijmegen, The Netherlands \\ ${ }^{c}$ Department of Health Care Studies, University of Maastricht, P.O. Box 616, 6200 MD Maastricht, The \\ Netherlands
}

\begin{abstract}
Aim: Assessing the usefulness of GP electronic medical records for assessing the health of rural populations by comparing these data with data from health interview surveys.

Data: Data from electronic medical records routinely recorded in general practices in 2000 2002. Data on self-reported health problems were obtained through questionnaires in a subset of the same patient population.

Results: According to GP-records, acute somatic and chronic diseases were more frequently presented in rural areas. At the same time self reported health problems point to a better health in rural areas.

Conclusion: GP electronic medical records may be used to monitor the health of rural populations. These data can be obtained relatively quickly and easily and against acceptable cost. However, they do not give the same outcomes as health interview surveys. Reasons for this discrepancy may be; differences in the accessibility of specialist services and help seeking behaviour between urban and rural populations.
\end{abstract}

\section{INTRODUCTION}

In the developed (post-) industrialized world urbanicity is often found to be related to health status of the population. It is generally found that in modern industrialized societies (self reported) health status, and especially mental health status is worse in urban areas than in rural areas ([Caldwell et al., 2004], [Larson and Correa-de-Araujo, 2006], [Maas et al., 2006], [Verheij et al., 2008] and [Weich et al., 2006]).

Utilisation of all sorts of health services is usually found to be higher in urban areas too, though this may not only be a result of health differences but also of differences in access to health services in urban areas or help seeking behaviour. In line with the classic studies by Milgram (1970) and Wirth (1938) urbanicity is often found to be associated with deprivation, violence, concentrations of ethnic minorities and environmental health hazards, whereas the rural element is associated with salutogenic factors like 'space', fresh air and a green and healthy environment (Maas et al., 2006).

Studies on the health of farmers in the Netherlands and Finland showed that farmers had fewer health problems than the rest of the working population ([Nielen et al., 2008], [Stiernstrom et al., 2001] and [Thelin et al., 2009]). The studies in Finland showed that the rural non-farming population was healthier compared to the urban population, except for musculoskeletal disorders (Thelin et al., 2009). This raised the 
Kroneman, M., Verheij, R., Tacken, M., Zee, J. van der. Urban-rural health differences: primary care data and self reported data render different results. Health and Place: 2010

question whether only farmers experienced fewer health problems than urban residents or whether this observation is valid for the rural areas population as a whole.

On the other hand, the health of rural populations is at risk. Increasing antibiotic resistance, outbreaks of foot-and-mouth disease, avian flu, Q-fever and swine flu impose serious physical as well as mental health threats to especially rural populations. Dutch rural areas are relatively densely populated compared to rural areas in other parts of the world. In combination with high concentrations of animals as a result of intensive livestock farming (poultry, pigs and goats) in these areas this may impose a significant and new threat to public health. The recent (autumn 2009) outbreak of Q-fever in a goat farming area in the Netherlands has made this all the more clear. Under these circumstances it is wise to keep a close watch on the health of especially rural populations.

Most studies dealing with urban-rural health differences in Western Europe are based on people's perceived general health and/or are limited to specific health problems or focus on specific subgroups in the population (see for instance: [Iversen et al., 2005], [Koskimaki et al., 1998], [Lehtinen et al., 2003], [Minelli et al., 2007], [O'Reilly et al., 2007], [Olowokure et al., 2006] and [Paykel et al., 2003]). Very few studies on urban-rural health differences cover the whole population and the whole range of health problems. Besides, data are often collected on the basis of questionnaires or health interview surveys, which are time consuming and expensive. Also, real time health monitoring (necessary given the current health threats) is not a viable option using health interview surveys.

Routine data from GP electronic medical records may resolve this problem, especially in health care systems where virtually all inhabitants are listed with a GP, where GPs are usually the first to consult for all health problems and specifically in countries where GPs have a gatekeeping role for secondary care such as the Netherlands and the UK. Using GP electronic medical records for investigating geographic health differences has obvious advantages above other data sources such as health interviews (expensive) mortality or hospital data (only serious health problems).

The purpose of this paper is to identify rural-urban differences in the prevalence of specific (clusters of) diseases by using GP-based routine electronic medical records and thereby to assess the potential of such data for monitoring urban-rural health differences. The outcome of these analyses may be influenced by variations in the availability of health services and help seeking behaviour. On the other hand, EMR data may render more valid results because they are based on diagnoses made by doctors. Both types of data have their limitations. Therefore, we compare the results of this analysis data from health interview surveys in order to test the validity of the outcomes from EMR data.

Differences between EMR data and self reported health have been investigated before. Self reported prevalence of for example diabetes appeared to largely coincide with EMR data. With respect to asthma/COPD and heart failure the agreement was moderate compared to the medical records. For myocardial infarction the results varied across studies (Klungel et al., 1999; Mohangoo et al., 2006; Okura et al., 2004). It is unknown, however, to what extent this affects urban-rural differences. The second purpose of this paper is to investigate whether urban-rural differences are congruent between self-reported health measures and primary care EMRs.

The following research questions will be addressed:

Which health problems presented to GPs can be identified as typical for urban or rural areas (as based on routine GP electronic medical records)?

To what extent do the results of these analyses correspond with similar analyses based on health interview surveys?

\section{METHODS}

\subsection{Study population}

Data were derived from the Second Dutch National Survey of General Practice (DNSGP-2). The DNSGP2 was conducted in 2000-2002 in 104 general practices consisting of 195 GPs and 385,461 listed patients (2.5\% of the population of GPs and $2.5 \%$ of the total Dutch population (Westert et al., 2005)). Patients are representative for the Dutch population with respect to age, gender and type of health care insurance (Westert et al., 2005). GPs are representative for the Dutch population of GPs with respect to university of education, urbanicity, practice type (single handed or not, dispensing or not) and gender. Among participating GPs there was a slight overrepresentation of age 45-54 and of doctors from group practices compared to single handed practitioners. Data comprising all morbidity presented in all consultations that 
Kroneman, M., Verheij, R., Tacken, M., Zee, J. van der. Urban-rural health differences: primary care data and self reported data render different results. Health and Place: 2010

took place during a 12 month period in these practices were extracted from their computer systems. In addition, for all health problems presented, GPs indicated whether this was a new or an existing health problem, in order to be able to distinguish incident from prevalent cases.

Practices recorded all morbidity during a period of 12 months. The first practice started the registration in the second quarter of 2000, the last practices started the registration in the second quarter of 2002 (Schellevis et al., 2004).

The data on self-reported health were collected in 2001 via face-to-face interviews by a subset of the listed patient population of the general practices that participated in the DNSGP-2. Per full-time GP at least 80 patients were interviewed, resulting in 12,699 respondents (response rate 64.5\%). To avoid seasonal influences, the interviews were spread over the four trimesters of the year. In comparison with the Dutch population (data for January 2001 from Statistics Netherlands), there is a slight overrepresentation of females (54.0\% of the respondents, compared to $50.5 \%$ in the Dutch population) and an underrepresentation of the age-group 20-39 (22.9\% in the study population, compared to $30 \%$ in the Dutch population) and there are slightly more persons evaluating their health as 'good' in the study population ( $84 \%$ compared to $80.5 \%$ in the Dutch population).

\subsection{Operationalisation}

\subsubsection{Patients}

Patients in our study are all individuals listed in one of the practices participating. This includes persons that did not actually consult their GP in the study period. Since virtually all residents of the Netherlands are listed with a GP, this can be regarded as a sample of the population.

\subsubsection{Episodes of care}

Morbidity was recorded using International Classification of Primary Care (ICPC). Consultations concerning the same health problem were clustered into episodes of care by a team of medical students (Biermans et al., 2008), resulting in 949,220 episodes. An episode of care is defined as the period from the first presentation of a health problem or illness to a health care provider until the completion of the last encounter for that same health problem or illness (Schellevis et al., 2004).

\subsubsection{Disease clusters}

The ICPC coding system distinguishes of more than 700 complaints or diseases in 17 chapters that are named after medical tract (e.g. respiratory, musculoskeletal, urinary tract). We considered clustering of diseases necessary in order to provide a manageable overview of the results. For this study we chose to use a clustering of diseases based on type of disease rather than medical tract. This clustering (see Appendix A) has been used in previous studies and is based on communalities in type of health care needed, type of health complaints and impairments ([De Bakker et al., 2005] and [Verheij et al., 1992]). Disease clusters with a prevalence of less than $0.5 \%$ were not taken into account. As a result, the categories Congenital disorders and Disabilities were not included in the analyses. The category Other was also removed because the included diagnoses were too diverse. This resulted in the following diseases clusters to be included in this study:

$\begin{array}{ll}\text { Acute somatic diseases } & \text { Social problems } \\ \text { Traumata } & \text { Prevention } \\ \text { Infections } & \text { Mental disorders } \\ \text { Chronic diseases } & \text { Side effects } \\ \text { Neoplasms } & \text { Fear of diseases }\end{array}$

The cluster 'side effects' refers to adverse effects of treatment or medication. The most prevalent disease clusters (traumata, chronic diseases, acute somatic diseases and infections), were subdivided into more detailed disease groups, based on the medical tract or organ involved. A more detailed description of disease clusters is presented in Appendix A. 
Kroneman, M., Verheij, R., Tacken, M., Zee, J. van der. Urban-rural health differences: primary care data and self reported data render different results. Health and Place: 2010

\subsubsection{Self-reported health status}

In the health interview surveys respondents were asked whether in the past two weeks they had suffered from acute complaints like headache, fatigue, palpitations of the heart, dizziness, insomnia, excessive sweating, tinnitus, impaired hearing, fever, sore throat, a stuffy nose, earache, coughing, short of breath/tightness of the chest, a touch of flu, stomach-ache, nausea, pain on the chest, warts, itching, diarrhoea, heartburn, abdominal pain/cramp, constipation, weight gain, local redness of the skin, local swelling of the skin, pain in the neck/shoulder/upper back, low back pain, pain in (one of the) elbows/wrists/hands, pain in (one of the) hips/knees, other complaints. Responses were dichotomised into no complaints versus one or more complaints. For mental health problems, the 12 -item General Health Questionnaire was used (Goldberg, 1972) in the Dutch version (Koeter and Ormel, 1991). Also GHQ scores were dichotomised ( $0-1$ versus $\geq 2)$ to identify possible psychiatric cases (Goldberg et al., 1997). In addition, the respondents were asked to evaluate their own health condition on a five point scale (based on SF-36). Having acute somatic health problems was dichotomised into 'good' (comprising the categories 'excellent', 'very good' and 'good') and 'mediocre/bad'. For chronic conditions, the respondents were asked whether they (ever) had: diabetes, stroke, myocardial infarction, other severe heart conditions in the past 12 months, cancer, migraine/severe headache in the past 12 months, high blood pressure in the past 12 months, constriction of the blood vessels in leg or stomach, asthma/chronic bronchitis/COPD/CARA, psoriasis in the past 12 months, chronic eczema in the past 12 months, dizziness with falling in the past 12 months, severe conditions of the intestines (longer than three months), incontinence, serious conditions of the back (slipped disc), arthritis of hip/knee, chronic arthritis, other serious conditions of the neck/shoulder, other severe conditions of elbow/hand/wrist and other chronic conditions. Having a chronic health problem was dichotomised into having none of these chronic conditions and having one or more chronic conditions.

\subsubsection{Prevention and influenza vaccination}

As it is likely that a future influenza epidemic will start off in rural areas, we decided to also look at influenza vaccination uptake. In the Netherlands, every year influenza vaccination for high risk populations is offered free of charge and is administered by GPs. Influenza vaccination is a seasonal activity that is recorded somewhat differently from other episodes. Dutch general practices use an automatic module in the computerized medical record system that is called the influenza vaccination module (griepmodule). This module facilitates the selection and registration of the vaccination status of persons for whom vaccination is recommended. Eligible patients for an influenza vaccination were identified on the basis of information recorded in the GP computer systems, using ICPC codes, indication tags and prescriptions to identify highrisk patients. Subsequently they were invited by GPs to be vaccinated. (Hak et al., 1998; [Tacken et al., 2002] and [Tacken et al., 2004]). Influenza vaccination data for the 2001 influenza season were collected in 50 practices that participated in the DNSGP-2. The vaccination status of patients who are at high risk for influenza according to the immunisation guidelines of the Dutch College of General Practitioners that were valid at that moment ([Van Essen et al., 1993] and [Van Essen et al., 1997]) were added to our dataset (matching on practice no. and patient no.). Information on influenza vaccination status of persons not at risk was not available. The subset of 50 practices did not differ from the other 54 practices in the DNSGP-2 with respect to the following characteristics: number of GPs in FTE, urbanity and number of patients. For the disease cluster prevention we used only the 50 practices (comprising of in total 204.118 patients) for which also influenza vaccination data were available. A more detailed description of the Dutch influenza vaccination programme and the registration of the vaccination event in the computerized EMR system can be found in Appendix B.

\subsubsection{Urbanicity}

We use the term urbanicity to describe the extent to which an area is urban or rural ([Verheij, 1996] and [Vlahov and Galea, 2002]). Urbanicity refers to the impact of living in urban areas at a given time rather than the process of urbanization. Urbanicity is operationalised as address density, divided into five classes, ranging from rural (less than 500 addresses per $\mathrm{km}^{2}$ ) to highly urban (more than 2500 addresses per $\mathrm{km}^{2}$ ) (Den Dulk et al., 1992). Urbanicity for every 4 digit postcode area in the Netherlands was obtained from Statistics Netherlands and linked to our dataset using the 4 digit postcode of GP practices. We included all five categories in our analyses but focussed on the difference between the least urban (rural) areas (less than 500 addresses per $\mathrm{km}^{2}$ ) and the most highly urbanized areas (urban; over 2500 addresses per $\mathrm{km}^{2}$ ) (Den Dulk et al., 1992). The distribution of patients and practices over the different levels of urbanicity is 
Kroneman, M., Verheij, R., Tacken, M., Zee, J. van der. Urban-rural health differences: primary care data and self reported data render different results. Health and Place: 2010

displayed in Table 1. [Fig. 1], [Fig. 2], [Fig. 3] and [Fig. 4] show the prevalence of the disease clusters of the three categories in between rural and urban as summarized in one figure.

\section{[TABLE 1, FIGURE 1, FIGURE 2, FIGURE 3, FIGURE 4]}

\subsubsection{Analyses}

The difference between rural and urban areas in disease prevalence was analysed with multilevel logistic regression models distinguishing patient and practice level. Outcomes are expressed in terms of odds ratios, with disease prevalence as dependent variable and urbanicity (reference category: urban: over 2500 inhabitants within $1 \mathrm{~km}$ radius, dummy variables for each level of urbanity) as independent variable. Males and females were analysed separately. Age was included as confounding variable. Survey data and data from EMRs were analysed in the same way. In order to make the results as comparable as possible, we considered it important to use exactly the same analyses (in practice this implied taking GP-practice as separate level) in our multi-level model. In addition in the literature we found support for the influence of quality and supply of primary care on self-reported health, indicating that the level of GP-practice might influence self-reported health status ([Macinko et al., 2003] and [Starfield et al., 2005]). We compared the subjective 'acute somatic problems' with the cluster 'Acute somatic diseases', the GHQ-score with the cluster 'Mental disorders' and the subjective chronic health problems with the cluster 'Chronic diseases'.

\section{RESULTS}

\subsection{Rural-urban differences in broad disease clusters}

For males, traumata, chronic diseases, acute somatic diseases, infections, family planning and neoplasms are more often recorded by GPs in rural areas (see Fig. 1 and Table 2). For females, the prevalence of chronic diseases, infections and traumata was higher in rural areas than in urban areas (see Fig. 2 and Table 2). These differences are to some extent gender specific: the urban-rural difference for traumata was larger for males (odds ratio 3.31) than for females (odds ratio 2.62). For acute somatic health problems, family planning issues and neoplasms, the difference between urban and rural was significant for males only. There was no urban-rural difference in the recorded mental health problems for both males and females.

\section{[TABLE 2.]}

The intermediate urbanization levels sometimes show larger differences with either the rural or urban category compared to the difference between rural and urban on which we focus in this study. We do not enter into this matter further.

\subsection{Rural-urban differences in more detailed health clusters}

The four disease clusters with the largest differences between rural and urban population were further subdivided: traumata, infections, chronic diseases and prevention. The category 'infections' was subdivided into type of infection and part of the body. The categories 'traumata' and 'chronic diseases' were subdivided according to the organ system. In the category 'prevention' the prevention of influenza for the so-called high risk population (influenza vaccination administered by the GP) was selected (see Table 3 and [Fig. 3] and [Fig. 4]).

\section{[TABLE 3.]}

\subsection{Traumata more detailed}

For males, traumata of the eye, skin and musculoskeletal system were more prevalent in rural areas and for females these were traumata of the ear, eye, skin, neurological system and musculoskeletal system.

\subsection{Infectious diseases more detailed}

For males, GPs in rural areas more often recorded infections of the glands (ICPC-codes A75 and B70-71), ear, respiratory tract and skin infections. For females in rural areas, the same top 4 infection types (glands, ear, skin and respiratory tract) existed for disease categories concerning infections as for males. In addition, for women, urinary tract infections and infections of the eye were more often registered in rural practices. 
Kroneman, M., Verheij, R., Tacken, M., Zee, J. van der. Urban-rural health differences: primary care data and self reported data render different results. Health and Place: 2010

\subsection{Acute somatic diseases more detailed}

GPs in rural areas recorded for males more often acute somatic diseases of the musculoskeletal system, acute somatic general or unspecified diseases and acute somatic diseases of the eye. For females the only significant rural-urban difference was recorded for acute somatic diseases of the blood system.

\subsection{Chronic diseases more detailed}

For chronic diseases, musculoskeletal and ear problems were the most prevalent in rural areas for both males and females. Females more often presented chronic conditions of the circulatory system and the genital system (chapter X and Y, ICPC) rural GPs whereas chronic diseases of the metabolism were presented more often in the rural male population.

\subsection{Influenza vaccination}

No differences in the prevalence of influenza vaccination were found between the urban and rural socalled high risk populations; neither for males nor for females.

\subsection{GP-recorded health issues versus self assessed health indicators}

The analyses based on GP electronic medical records give the impression that rural populations are generally less healthy than urban populations. However, health interview surveys render totally different results. Self assessed general health is generally better in rural females (Table 2). And while EMR data show no rural/urban difference in mental health problems, rural residents themselves report a better mental health. Rural males as well as females report fewer acute complaints than urban residents. Yet, EMR data show more acute somatic conditions in rural areas (but not for women). Similarly, EMRs in rural practices show more chronic conditions for both males and females and yet rural residents do not more often report such chronic conditions themselves when asked.

\section{DISCUSSION AND CONCLUSIONS}

Morbidity presented in general practice and recorded in electronic medical records appeared to vary between urban and rural areas. Differences found were always to the disadvantage of the rural areas (traumata, chronic diseases and infections). For some health problems the difference was gender specific: for traumata, the urban-rural difference was much larger in men than in women. For acute somatic diseases, family planning issues (for males this is mainly sterilization) and neoplasms differences were only found in for men (more in rural areas).

In the international literature there is support for our findings indicating a more frequent use of health services and higher disease prevalence in rural areas ([Dempsey et al., 2003], [O'Reilly et al., 2007] and [Ramsey and Glenn, 2002]). Specific health risks in rural areas may relate to the agricultural nature of most of these areas, especially when close contact with animals, working with heavy machinery and heavy physical labour are involved (see for instance Larson and Correa-de-Araujo (Larson and Correa-de-Araujo, 2006)). Working in close contact with animals is sometimes associated with a higher risk of diseases like avian influenza or MRSA. At the time of writing this paper (the beginning of 2010), there is a serious outbreak of Q-fever in the Netherlands, that is spread through goat farming. Working with animals, heavy machinery and heavy physical labour may be associated with a higher risk of traumata and chronic conditions in rural areas (see for instance (Hider et al., 2007; Leff et al., 2003)). This may outweigh high traffic density and industrial labour in urban areas (see for example Cooley and Jones (2002)). Another explanation for the lower incidence of traumata in urban areas could be that hospital emergency departments are more easily accessible and more frequently used in urban areas. Contrary to what is usually reported in the literature, the EMR data did not reveal significant differences in the prevalence of mental health problems.

In sum, primary care data collected through electronic medical records show considerable differences between urban and rural areas, to the disadvantage of the rural areas. Data from health interview survey on the other hand, reveal a different pattern. Rural populations evaluate their health status more often as "good". Fewer rural inhabitants run the risk of having mental health problems and report acute complaints less often. In addition, the rural population does not more often report chronic conditions.

There are several possible explanations for the discrepancy between self reported illness and data based on GP consultations. First, general practice may play a more central role in rural areas. Longer travel distances (even in the densely populated Netherlands) may result in fewer referrals to specialist care in rural areas. For the same reason, patients who are referred may come back under treatment of general practitioners 
Kroneman, M., Verheij, R., Tacken, M., Zee, J. van der. Urban-rural health differences: primary care data and self reported data render different results. Health and Place: 2010

more quickly. This may be an important explanation for the discrepancies found for chronic diseases, acute somatic problems and mental health problems. Similarly, for urban populations it will be easier to go to a hospital emergency department in case of traumata, while for rural populations, the GP might be the most choice. We presume that better accessibility of more specialised health services in urban areas causes morbidity to 'leak' from general practice into these more specialised services.

An additional explanation may be a difference in attitudes towards health problems which may lead to under-reporting in rural areas. People in rural areas might be less inclined to tell an interviewer about their health problems. This may be particularly true for mental health problems. This explanation, however, is not wholly unproblematic, as the same difference would probably also cause rural populations to be less inclined to visit a doctor for their health problems.

Finally, there may also be methodological differences causing discrepancies in urban-rural variations in health status. The EMR data were collected during a 12 month period, whereas in the interviews people were asked about health problems in the past 2 weeks. Also, the self reported health problems may also include less severe problems, for which people do not visit their GP. However, we find it difficult to envisage how this may explain the discrepancies in outcomes in EMR data and self reported data.

In the light of the newly emerging diseases, and more specifically avian flu (H5N1) and swine flu, influenza vaccination is an important issue for rural areas. No difference was found in influenza vaccination uptake between urban and rural areas, although respiratory infections appeared to be more prevalent in rural areas. At present no systematic information on influenza vaccination uptake among for instance farmers involved in cattle breeding is available in routinely collected data in general practice.

\subsection{Limitations}

Routinely collected GP electronic medical records give information about health problems presented in general practice, but the aetiology of diseases usually remains unseen. For example, the type of virus causing an infection is usually not routinely recorded by the GP in a way that is useful for research. Also the occupational background of the patients is not available in routinely collected data, making it difficult to distinguish for example the farming population from the non-farming population. Since, for instance, cattle breeding is associated with an increased risk for zoonoses, it is important to monitor these emerging diseases. The recent developments with respect to Q-fever in the eastern part of the Netherlands make this clear. The data recorded at general practice could contribute to giving direction to further research.

Differences between rural and urban areas are often associated with differences in socio-economic background of the population (Auchincloss and Hadden, 2002). As this may have affected our results, we repeated our analyses (not presented here), including socio-economic position (based on the International Socio-Economic Index of Occupational Status (ISEI92, Ganzeboom and Treiman, 1996)) and education. The results were similar to the ones presented here. Although the differences between rural and urban were somewhat smaller they were still significant, except for infections of the skin for males and traumata of the neurological system for females.

An important methodological limitation is the dichotomisation of the outcome indicators. Since for this study we were interested in whether there were urban-rural differences in having health complaints, we decided to use this simplification. In further research, attention for differences in the number of complaints in each disease category between urban and rural inhabitants is recommended.

Our results showed that there is a considerable variation in the influence of GP-level on GP-recorded health complaints. Since this was not the focus of this study, we did not explore this further. However, in future research, the influence of GP and service level characteristics on the difference between EMR and health interviews should be explored further.

In this study, we focussed on health differences between urban and rural areas. However, the sub-urban categories were also included in the analyses. As can be seen in [Fig. 1], [Fig. 2], [Fig. 3] and [Fig. 4], the sub-urban categories do not always show a consistent pattern, in the sense that the prevalence in these categories is in between the prevalence in rural and urban areas. We have no explanation for this.

\section{CONCLUSION}

We conclude that routine electronic medical records are a useful source of information on the health of rural (and urban) populations. It is possible to identify health problems that are specific for these two types of areas. The type of health problems in rural areas may relate to the agricultural environment (especially in the Netherlands, where most rural areas are agricultural areas), although, according to recent findings, those 
Kroneman, M., Verheij, R., Tacken, M., Zee, J. van der. Urban-rural health differences: primary care data and self reported data render different results. Health and Place: 2010

who work as farmers report a better health compared to the working population as a whole (Nielen et al., 2008).

An important advantage of GP EMRs in health systems like the Netherlands and the UK is that they refer to the population as a whole, not to the selected subpopulation e.g. from occupational health sources. In addition, electronic medical records in the Netherlands also hold information on influenza vaccination status of the population. All this can be important for, e.g., monitoring the spread of infectious diseases, since these can spread to family members and neighbours as well, as the recent outbreak of Q-fever clearly points out. Routine recording of additional background information on for example people's profession, in high risk areas may offer better insight into the aetiology of specific rural health problems.

However, our analysis on self reported health problems also points out that there is also a risk in relying on GP data. Even in health systems where GPs are gate-keepers for secondary care, in urban areas the vicinity of other health services (like the emergency department and mental health care institutes) may attract people to go to these services directly.

We recommend that future studies distinguish between diseases that are and are not sensitive to differences in the accessibility of specialised health services and specialised acute care services. Another option to investigate this issue further is to include not only information from general practitioners but also from other health care services, such as out-of-hours services and hospital emergency departments, and see whether the discrepancy in outcomes between self reported health and data from electronic medical records pertains.

\section{APPENDIX A: THE CLUSTERING OF ICPC-CODES IS SHOWN IN TABLE A1 HERE.}

Table A1.

Clustering of ICPC-codes into disease clusters.

\begin{tabular}{|c|c|c|}
\hline \multirow[t]{3}{*}{ Congenital disorders } & & A90, B78-79, D81, F80-81 \\
\hline & & H80, K73, L82, N85, R89, S83, T78, T80, \\
\hline & & W76, X83, Y82-84 \\
\hline \multirow[t]{12}{*}{ Acute somatic diseases } & General & A01-11, A14-15, A29, A91 \\
\hline & Blood & B01-04, B11, B29, B84-87 \\
\hline & Gastro-intestinal & D01-25, D29, D83-86, D90 D96 \\
\hline & Eye & F01-18 F29 F82-85 \\
\hline & Ear & H01-15, H29 \\
\hline & Circulatory system & K01-07 K29 \\
\hline & $\begin{array}{l}\text { Musculoskeletal } \\
\text { system }\end{array}$ & L01-25 L29 \\
\hline & Neurological & N01-19, N29, N89, N90-94 \\
\hline & Respiratory tract & R01-25, N29 \\
\hline & Skin & S01-08, S20-24, S29 \\
\hline & Endocrinal & $\mathrm{T} 01-11, \mathrm{~T} 15, \mathrm{~T} 29$ \\
\hline & Urinary tract & U01-14, U29 \\
\hline
\end{tabular}


Kroneman, M., Verheij, R., Tacken, M., Zee, J. van der. Urban-rural health differences: primary care data and self reported data render different results. Health and Place: 2010

\begin{tabular}{|c|c|c|}
\hline & Genital system female & X01-21, X29, X84-88 \\
\hline & Genital system male & Y01-10, Y16, Y29 \\
\hline \multirow[t]{10}{*}{ Traumata } & General & A80-82, A86, A88-89 \\
\hline & Blood & B76-77 \\
\hline & Eye & F75-79 \\
\hline & Ear & H76-79 \\
\hline & $\begin{array}{l}\text { Musculoskeletal } \\
\text { system }\end{array}$ & L72-80, L81, L96 \\
\hline & Neurological & N79-81 \\
\hline & Respiratory tract & $\mathrm{R} 87-88$ \\
\hline & Skin & S12-19 \\
\hline & Genital system & $\mathrm{X} 82, \mathrm{Y} 80$ \\
\hline & Other & D79, D80, K72, T74, W75, U80 \\
\hline \multirow[t]{13}{*}{ Infections } & Children's diseases & A71-72 A74 D71 N70-71 R71-72 \\
\hline & Glands & A75 B70-71 \\
\hline & Gastro-intestinal & D70, D73, D74, D88 \\
\hline & Eye & F70-73 \\
\hline & Ear & $\mathrm{H} 70-74$ \\
\hline & Circulatory system & $\mathrm{K} 70, \mathrm{~K} 74$ \\
\hline & $\begin{array}{l}\text { Musculoskeletal } \\
\text { system }\end{array}$ & L70 \\
\hline & Respiratory tract & R74-83, R90 \\
\hline & Skin & S09-11, S70-76, S84-85 \\
\hline & Urinary tract & U70, U71, U72 \\
\hline & Genital system female & X70-74, X90, X99 \\
\hline & Genital system male & Y70-75 \\
\hline & Other & A70, A73, A76-A78, B90, L70, N72-73, R70, R73, T70 \\
\hline
\end{tabular}


Kroneman, M., Verheij, R., Tacken, M., Zee, J. van der. Urban-rural health differences: primary care data and self reported data render different results. Health and Place: 2010

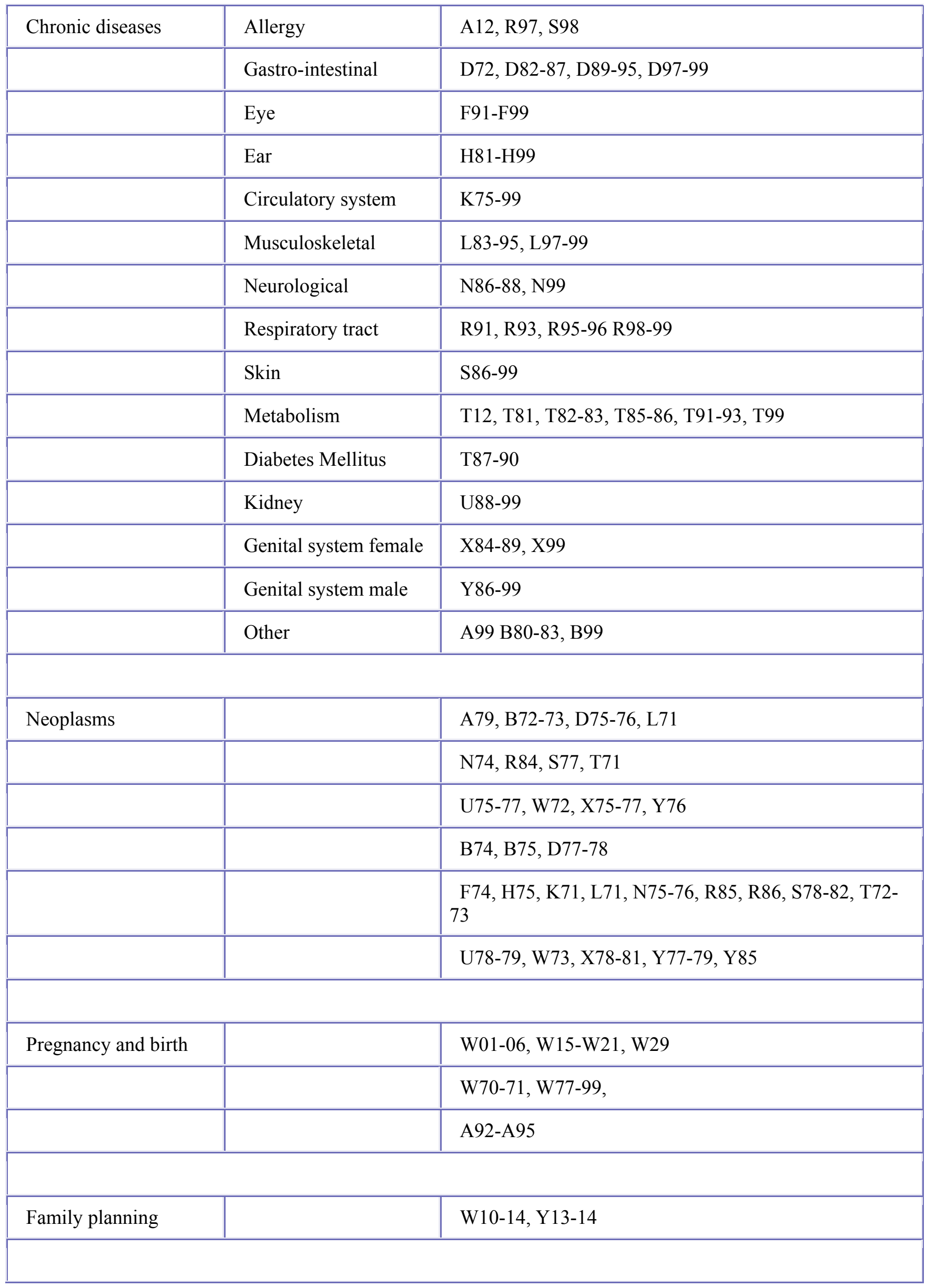


Kroneman, M., Verheij, R., Tacken, M., Zee, J. van der. Urban-rural health differences: primary care data and self reported data render different results. Health and Place: 2010

\begin{tabular}{|c|c|c|}
\hline \multirow[t]{9}{*}{ Fear for diseases } & & A13, A23-27 \\
\hline & & B25-27 \\
\hline & & D26-27, F27 \\
\hline & & H27,K24-27 \\
\hline & & L26-27 \\
\hline & & N26-27, P27 \\
\hline & & R26-27, S26-27 \\
\hline & & T26-27, U26-27 \\
\hline & & W27, X23-27, Y24-27, Z27 \\
\hline \multirow[t]{3}{*}{ Mental disorders } & & P01-13 \\
\hline & & P15-26, P29 \\
\hline & & P70 -99 \\
\hline Social problems & & Z01-29 \\
\hline Side effects & & A83-87 \\
\hline \multirow[t]{11}{*}{ Prevention } & & A30-31 \\
\hline & & A44-45, A49 \\
\hline & & B44-45, B49 \\
\hline & & D44-45, D49 \\
\hline & & F44-45, F49 \\
\hline & & H44-45, H49 \\
\hline & & K44-45, K49 \\
\hline & & L44-45, L49 \\
\hline & & N44-45, N49 \\
\hline & & P44-45, P49 \\
\hline & Influenza vaccination & R44 (via special data collection procedure) \\
\hline
\end{tabular}


Kroneman, M., Verheij, R., Tacken, M., Zee, J. van der. Urban-rural health differences: primary care data and self reported data render different results. Health and Place: 2010

\begin{tabular}{|c|c|}
\hline & R45, R49 \\
\hline & S44-45, S49 \\
\hline & T44-45, T49 \\
\hline & U44-45, U49 \\
\hline & W44-45, W49, W30-31 \\
\hline & $\mathrm{X} 44-45, \mathrm{X} 49 . \mathrm{X} 37$ \\
\hline & Y44-45, Y49 \\
\hline & Z44-45, Z49 \\
\hline \multirow[t]{2}{*}{ Disabilities } & A28, B28, D28, F28, H28, K28, L28, N28 \\
\hline & P28, R28, S28, T28, U28, W28, X28, Y28, Z28 \\
\hline \multirow[t]{17}{*}{$\begin{array}{l}\text { Minor surgery and } \\
\text { diagnostic procedures }\end{array}$} & A32-43 1046-47, A50-69 \\
\hline & B30-43, B46-47, B50-69 \\
\hline & D30-43, D46-47, D50-69 \\
\hline & F30-43, F46-47, F50-69 \\
\hline & H30-43, H46-47, H50-69 \\
\hline & K30-43, K46-47, K50-69 \\
\hline & L30-43, L46-47, L50-69 \\
\hline & N30-43, N46-47, N50-69 \\
\hline & P30-43, P46-47, P50-69 \\
\hline & R30-43, R46-47, R50-69 \\
\hline & S30-43, S46-47, S50-69 \\
\hline & T30-43, T46-47, T50-69 \\
\hline & U30-43, U46-47, U50-69 \\
\hline & W32-43, W46-47, W50-69 \\
\hline & X30-36, X38-43, X46-47, X50-69 \\
\hline & Y30-43, Y46-47, Y50-69 \\
\hline & Z30-43, Z46-47, Z50-69 \\
\hline
\end{tabular}


Kroneman, M., Verheij, R., Tacken, M., Zee, J. van der. Urban-rural health differences: primary care data and self reported data render different results. Health and Place: 2010

\begin{tabular}{|l|l|l|}
\hline \multicolumn{2}{|l|}{} & \\
\hline Other & $\begin{array}{l}\text { A16-17, A20, A96, A00, B00, D00, F00, H00, K00, } \\
\text { L00, N00 }\end{array}$ \\
\hline & P00, R00, S00, T00, U00, W00, X00, Y00, Z00 \\
\hline
\end{tabular}

\section{[APPENDIX B.] INFLUENZA VACCINATION IN DUTCH GENERAL PRACTICE}

The family physicians that participated in this study invited all their high-risk patients for annual immunisation in accordance with the immunisation guidelines of the Dutch College of General Practitioners ([Van Essen et al., 1993] and [Van Essen et al., 1997]). Box 1 describes the Dutch influenza programme.

Box 1. The Dutch influenza vaccination programme

In the Netherlands, primary health care is mainly provided by GP and nearly all Dutch inhabitants are listed with a GP. The GP staff keep a record of the vast majority of persons, including demographic and medical information.

In the Dutch influenza immunisation guidelines (Van Essen et al., 1997) vaccination is recommended for persons: aged 65 years or older, with cardiovascular disease, pulmonary or renal disease, diabetes or other immune-related disease at any age. Influenza vaccination is free of charge for all Dutch high-risk patients. There is a fee-for-service for the GPs who select, invite and vaccinate the population at risk, and document the vaccinations in the patients' medical records.

Annual influenza surveillance monitoring has been carried out by the National Influenza Centre in collaboration with the Sentinel Practice Network since 1970 (Rimmelzwaan et al., 2000) since 1996, vaccination rates have been monitored yearly by the National Information Network of General Practice (LINH) ([Tacken et al., 2002] and [Tacken et al., 2004]).

\section{B.1. Measurements of influenza vaccination}

Eligible patients for an influenza vaccination in 2001 were identified by means of a software module that searches through the EMR and uses ICPC codes, indication tags and prescriptions to identify high-risk patients. Elected patients were registered by means of an influenza indication tag. Details of the stepwise selection procedure have been reported previously (Hak et al., 1998). All relevant data were extracted from the EMR using specially developed software. All data were collected on a patient level. Contacts were defined as events in which a patient received professional advice or help from the family physician or practice assistant, including consultations, phone calls and home visits. Additional data were gathered on age, gender, type of health insurance (social health insurance or private health insurance), indications for vaccination according to the Dutch guidelines (Van Essen et al., 1997) (high-risk (co-) morbidity and/or age 65 years or older) and vaccination status.

\section{REFERENCES}

Auchincloss and Hadden, 2002 A.H. Auchincloss and W. Hadden, The health effects of rural-urban residence and concentrated poverty, J. Rural Health 18 (2) (2002), pp. 319-336.

Biermans et al., in press Biermans, M.C., De Bakker, D.H., Verheij, R.A., Gravestein, J.V., Van der Linden, M.W., Robbé, P.F., 2008. Development of a case-based system for grouping diagnoses in general practice. Int. J. Med. Inform. 77 (7), 431-439.

Caldwell et al., 2004 T.M. Caldwell, A.F. Jorm, S. Knox, D. Braddock, K.B. Dear and H. Britt, General practice encounters for psychological problems in rural, remote and metropolitan areas in Australia, Aust. N Z J Psychiatry 38 (10) (2004), pp. 774-780.

Cooley and Jones, 2002 H.M. Cooley and G. Jones, Symptomatic fracture incidence in southern Tasmania: does living in the country reduce your fracture risk?, Osteoporos. Int. 13 (4) (2002), pp. 317-322.

De Bakker et al., 2005 D.H. De Bakker, J.J. Polder, E.M. Sluijs, H.F. Treurniet, N. Hoeymans, L. Hingstman, M.J.J.C. Poos, R. Gijsen, D.J. Griffioen and L.F.J. Van der Velden, Op één lijn. Toekomstverkenning eerstelijnszorg 2020 [Exploring the Future of Primary Health Care in 2020], Rijksinstituut voor Volksgezondheid en Milieu, Bilthoven (2005). 
Kroneman, M., Verheij, R., Tacken, M., Zee, J. van der. Urban-rural health differences: primary care data and self reported data render different results. Health and Place: 2010

Dempsey et al., 2003 P. Dempsey, D. Wilson, A. Taylor and D. Wilkinson, Self-reported patterns of health services utilisation: an urban-rural comparison in South Australia, Aust. J. Rural Health 11 (2) (2003), pp. 81-88.

Den Dulk et al., 1992 C.J. Den Dulk, H. Van de Stadt and J.M. Vliegen, Een nieuwe maatstaf voor stedelijkheid: de omgevingsadressendichtheid [A new measure for degree of urbanization: the address density of the surrounding area], Maandstatistiek van de Bevolking 7 (1992), pp. 14-27.

Ganzeboom and Treiman, 1996 H.B.G. Ganzeboom and D.J. Treiman, Internationally comparable measures of occupational status for the 1988 international standard classification of occupations, Soc. Sci. Res. 25 (1996), pp. 201-239.

Goldberg, 1972 D.P. Goldberg, Detection of Psychiatric Illness by Questionnaire: a Technique for the Identification and Assessment of Non-Psychotic Psychiatric Illnesses, Oxford University Press, New York, Toronto (1972).

Goldberg et al., 1997 D.P. Goldberg, R. Gater, N. Sartorius, T.B. Ustun, M. Piccinelli, O. Gureje and C. Rutter, The validity of two versions of the GHQ in the WHO study of mental illness in general health care, Psychol. Med. 27 (1) (1997), pp. 191-197.

Hak et al., 1998 E. Hak, G.A. Van Essen, W. Stalman and R. De Melker, Improving influenza vaccination coverage among high-risk patients: a role for computer-supported prevention strategy?, Fam. Pract. 15 (2) (1998), pp. 138-143.

Hider et al., 2007 P. Hider, R. Lay-Yee and P. Davis, Doctors, practices, patients, and their problems during usual hours: a description of rural and non-rural primary care in New Zealand in 2001-2002, N Z Med. J. 120 (1253) (2007), p. U2519.

Iversen et al., 2005 L. Iversen, P.C. Hannaford, D.B. Price and D.J. Godden, Is living in a rural area good for your respiratory health? results from a cross-sectional study in Scotland, Chest 128 (4) (2005), pp. 2059-2067.

Klungel et al., 1999 O.H. Klungel, A. de Boer, A.H. Paes, J.C. Seidell and A. Bakker, Cardiovascular diseases and risk factors in a population-based study in The Netherlands: agreement between questionnaire information and medical records, Neth. J. Med. 55 (4) (1999), pp. 177-183.

Koeter and Ormel, 1991 M.W.J. Koeter and J. Ormel, General Health Questionnaire, Nederlandse Bewerking: Handleiding [General Health Questionnaire, Dutch version, Manual], Swets, Test Services, Lisse (1991).

Koskimaki et al., 1998 J. Koskimaki, M. Hakama, H. Huhtala and T.L. Tammela, Prevalence of lower urinary tract symptoms in Finnish men: a population-based study, Br. J. Urol. 81 (3) (1998), pp. 364-369.

Larson and Correa-de-Araujo, 2006 S. Larson and R. Correa-de-Araujo, Preventive health examinations: a comparison along the rural-urban continuum, Womens Health Issues 16 (2) (2006), pp. 80-88.

Leff et al., 2003 M. Leff, L. Stallones, T.J. Keefe, R. Rosenblatt and M. Reeds, Comparison of urban and rural non-fatal injury: the results of a statewide survey, Inj. Prev. 9 (4) (2003), pp. 332-337.

Lehtinen et al., 2003 V. Lehtinen, E. Michalak, C. Wilkinson, C. Dowrick, J.L. Ayuso-Mateos, O.S. Dalgard, P. Casey, J.L. Vazquez-Barquero and G. Wilkinson, Urban-rural differences in the occurrence of female depressive disorder in Europe-evidence from the ODIN study, Soc. Psychiatry Psychiatr. Epidemiol. 38 (6) (2003), pp. 283-289.

Maas et al., 2006 J. Maas, R.A. Verheij, P.P. Groenewegen, S. de Vries and P. Spreeuwenberg, Green space, urbanity, and health: how strong is the relation?, J. Epidemiol. Community Health 60 (7) (2006), pp. 587-592.

Macinko et al., 2003 J. Macinko, B. Starfield and L. Shi, The contribution of primary care systems to health outcomes within Organization for Economic Cooperation and Development (OECD) countries, 19701998, Health Serv. Res. 38 (3) (2003), pp. 831-865.

Milgram, $1970 \mathrm{~S}$. Milgram, The experience of living in cities. Adaptations to urban overload create characteristic qualities of city life that can be measured, Science 167 (3924) (1970), pp. 1461-1468.

Minelli et al., 2007 L. Minelli, F. Stracci, T. Cassetti, A. Canosa, M. Scheibel, I.E. Sapia, C. Romagnoli and F. La Rosa, Urban-rural differences in gynaecological cancer occurrence in a central region of Italy: 1978-1982 and 1998-2002, Eur. J. Gynaecol. Oncol. 28 (6) (2007), pp. 468-472.

Mohangoo et al., 2006 A.D. Mohangoo, M.W. Van der Linden, F.G. Schellevis and H. Raat, Prevalence estimates of asthma or COPD from a health interview survey and from general practitioner registration: what's the difference?, Eur. J. Public Health 16 (1) (2006), pp. 101-105.

Nielen et al., 2008 Nielen, M.M.J., Laan, Gvd, Pal, T., Verheij, R.A., 2008. Monitoring arbeid en gezondheid in de huisartsenpraktijk: een pilotstudy [Monitoring labour and health in general practice: a pilot study]. NIVEL, Utrecht.

O'Reilly et al., 2007 G. O'Reilly, D. O'Reilly, M. Rosato and S. Connolly, Urban and rural variations in morbidity and mortality in Northern Ireland, BMC Public Health 7 (147) (2007), p. 123.

Okura et al., 2004 Y. Okura, L.H. Urban, D.W. Mahoney, S.J. Jacobsen and R.J. Rodeheffer, Agreement between self-report questionnaires and medical record data was substantial for diabetes, hypertension, 
Kroneman, M., Verheij, R., Tacken, M., Zee, J. van der. Urban-rural health differences: primary care data and self reported data render different results. Health and Place: 2010

myocardial infarction and stroke but not for heart failure, J. Clin. Epidemiol. 57 (10) (2004), pp. 10961103.

Olowokure et al., 2006 B. Olowokure, H. Onions, D. Patel, J. Hooson and P. O'Neill, Geographic and socioeconomic variation in meningococcal disease: a rural/urban comparison, J. Infect. 52 (1) (2006), pp. 61-66.

Paykel et al., 2003 E. Paykel, R. Abbott, R. Jenkins, T. Brugha and H. Meltzer, Urban-rural mental health differences in Great Britain: findings from the National Morbidity Survey, Int. Rev. Psychiatry 15 (1-2) (2003), pp. 97-107.

Ramsey and Glenn, 2002 P.W. Ramsey and L.L. Glenn, Obesity and health status in rural, urban, and suburban southern women, South. Med. J. 95 (7) (2002), pp. 666-671.

Rimmelzwaan et al., 2000 G.F. Rimmelzwaan, J.C. De Jong, A. Bartelds, J.W. Dorigo-Zetsma, R.A. Fouchier and A.D. Osterhaus, Het influenzaseizoen 1999/2000 en de vaccinsamenstelling voor het seizoen 2000/01 [The Influenza season 1999/2000 and vaccine composition for the season 2000/01], Ned. Tijdschr. Geneeskd. 144 (41) (2000), pp. 1968-1971.

Schellevis et al., 2004 Schellevis, F. G., Westert, G. P., Bakker, D. H., Groenewegen, P. P., 2004. Tweede Nationale Studie naar ziekten en verrichtingen in de huisartspraktijk: vraagstellingen en methoden [Second National Study of General Practice: research questions and methods]. NIVEL, Utrecht.

Starfield et al., 2005 B. Starfield, L. Shi and J. Macinko, Contribution of primary care to health systems and health, Milbank Q. 83 (3) (2005), pp. 457-502.

Stiernstrom et al., 2001 E.L. Stiernstrom, S. Holmberg, A. Thelin and K. Svardsudd, A prospective study of morbidity and mortality rates among farmers and rural and urban nonfarmers, J. Clin. Epidemiol. 54 (2) (2001), pp. 121-126.

Tacken et al., 2002 M. Tacken, J. Braspenning, P. Spreeuwenberg, H. Van den Hoogen, G. Van Essen, D. De Bakker and R. Grol, Patient characteristics determine differences in the influenza vaccination rate more so than practice features, Prev. Med. 35 (4) (2002), pp. 401-406.

Tacken et al., 2004 M.A.J.B. Tacken, J.C.C. Braspenning, A. Berende, E. Hak, D. De Bakker, P.P. Groenewegen and R.P.T.M. Grol, Vaccination of high-risk patients against influenza: impact on primary care contact rates during epidemics. Analysis of routinely collected data, Vaccine 22 (23-24) (2004), pp. 2985-2992.

Thelin et al., 2009 N. Thelin, S. Holmberg, P. Nettelbladt and A. Thelin, Mortality and morbidity among farmers, nonfarming rural men, and urban referents: a prospective population-based study, Int. J. Occup. Environ. Health 15 (1) (2009), pp. 21-28.

Van Essen et al., 1997 G.A. Van Essen, M.M. Kuyvenhoven and R.A. De Melker, Implementing the Dutch College of General Practitioners' guidelines for influenza vaccination: an intervention study, Br. J. Gen. Pract. 47 (414) (1997), pp. 25-29.

Van Essen et al., 1993 G.A. Van Essen, Y.C.G. Sorgedrager, G.W. Slemink, Th.M.E. Govaert, J.P.H Van den Hoogen and J.R. Van der Laan, NHG-standard influenza en influenzavaccinatie. ["Dutch College of General Practitioners" guideline on influenza and influenza vaccination], Huisarts en Wetenschap 36 (10) (1993), pp. 342-346.

Verheij, 1996 R.A. Verheij, Explaining urban-rural variations in health: a review of interactions between individual and environment, Soc. Sci. Med. 42 (6) (1996), pp. 923-935.

Verheij et al., 1992 Verheij, R. A., De Bakker, D. H., Van der Velden, J., 1992. De huisarts in de grote stad [The General Practitioner in the city]. NIVEL, Utrecht.

Verheij et al., 2008 R.A. Verheij, J. Maas and P.P. Groenewegen, Urban-rural health differences and the availability of green space, Eur. Urban Reg. Stud. 15 (4) (2008), pp. 307-316.

Vlahov and Galea, 2002 D. Vlahov and S. Galea, Urbanization, urbanicity, and health, J. Urban Health 79 (Suppl. 1) (2002), pp. S1-S12.

Weich et al., 2006 S. Weich, L. Twigg and G. Lewis, Rural/non-rural differences in rates of common mental disorders in Britain: prospective multilevel cohort study, Br. J. Psychiatry 188 (2006), pp. 51-57.

Westert et al., 2005 G.P. Westert, F.G. Schellevis, D.H. De Bakker, P.P. Groenewegen, J.M. Bensing and J. Van der Zee, Monitoring health inequalities through general practice: the Second Dutch National Survey of General Practice, Eur. J. Public Health 15 (1) (2005), pp. 59-65.

Wirth, 1938 L. Wirth, Urbanism as a way of life, Am. J. Sociol. 44 (1) (1938), pp. 1-24. 
Kroneman, M., Verheij, R., Tacken, M., Zee, J. van der. Urban-rural health differences: primary care data and self reported data render different results. Health and Place: 2010

\section{TABLE AND FIGURE}

Table 1

Distribution of practices and patients over the levels of urbanity.

\begin{tabular}{lll}
\hline & No. of practices & No. of patients \\
\hline Very strongly urbanised (urban) & 22 & 64.415 \\
Strongly urbanised & 24 & 78.178 \\
Moderately urbanised & 20 & 82.884 \\
Little urbanised & 20 & 87.234 \\
Not urbanised (rural) & 18 & 72.750 \\
\hline
\end{tabular}

Fig. 1. Urban-rural differencesindiseaseprevalencein males (only significant differences areshown).

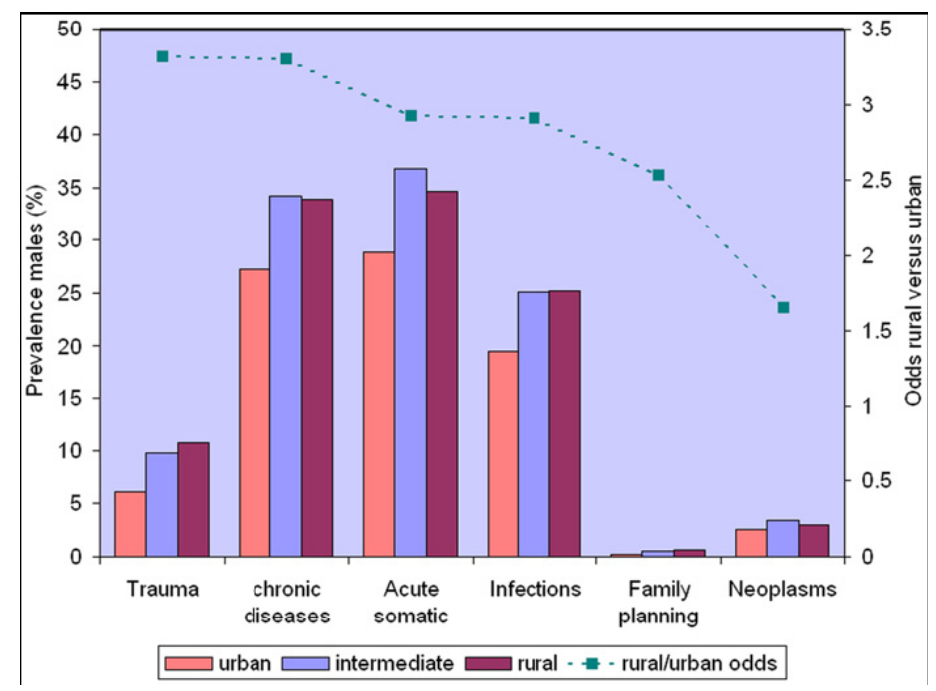

Fig. 2. Urban-rural differencesindiseaseprevalencein females (only significant differences areshown).

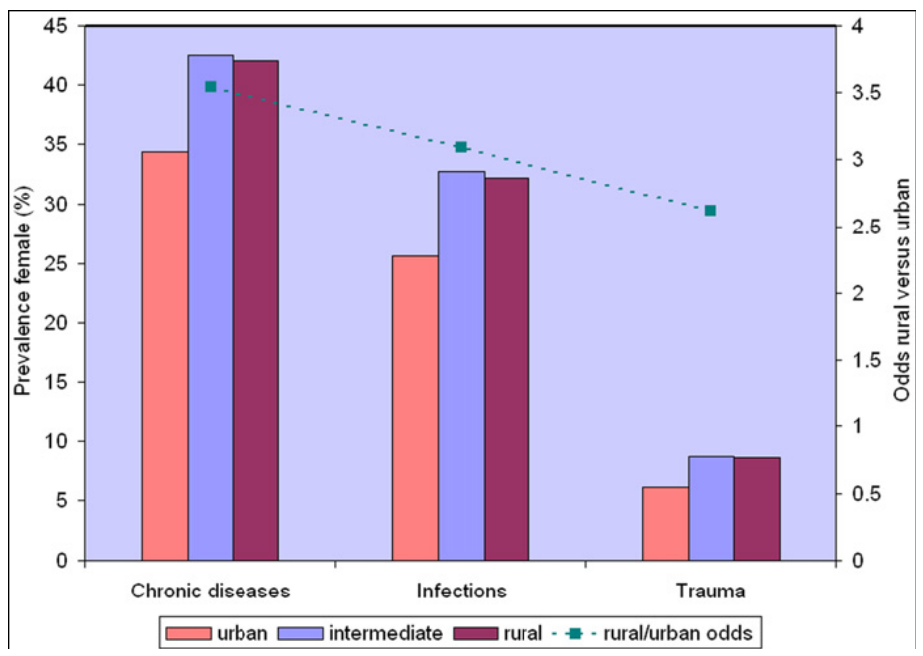

Fig. 3. Urban-rural differencesindiseaseprevalencein males for thediseaseclusterstrauma, infections, chronicdiseasesandacutesomaticdiseasesindetail(only significant differencesareshown). 
Kroneman, M., Verheij, R., Tacken, M., Zee, J. van der. Urban-rural health differences: primary care data and self reported data render different results. Health and Place: 2010

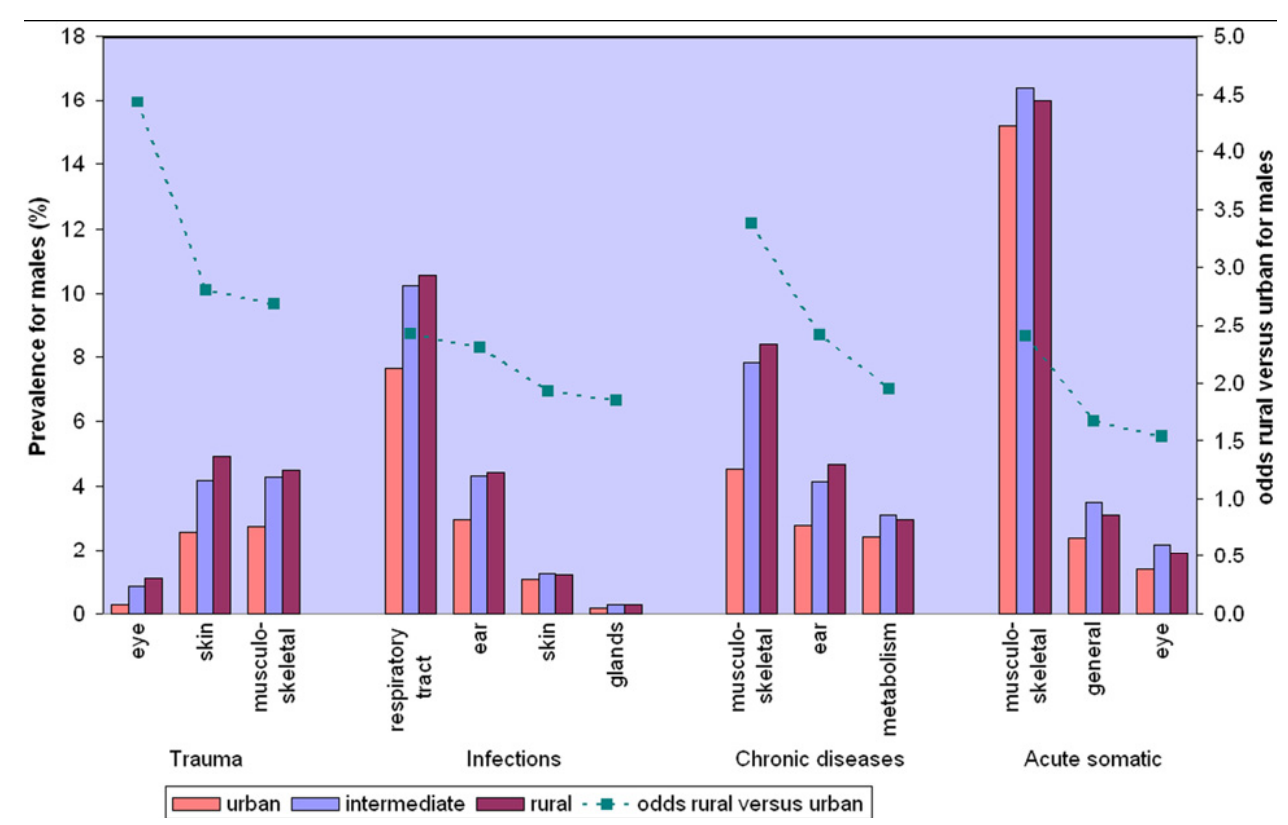

Fig. 4. Urban-rural differencesindiseaseprevalencein females for thediseaseclusterstrauma, infections, chronicdiseasesandacutesomaticdiseasesindetail(only significant differencesareshown).

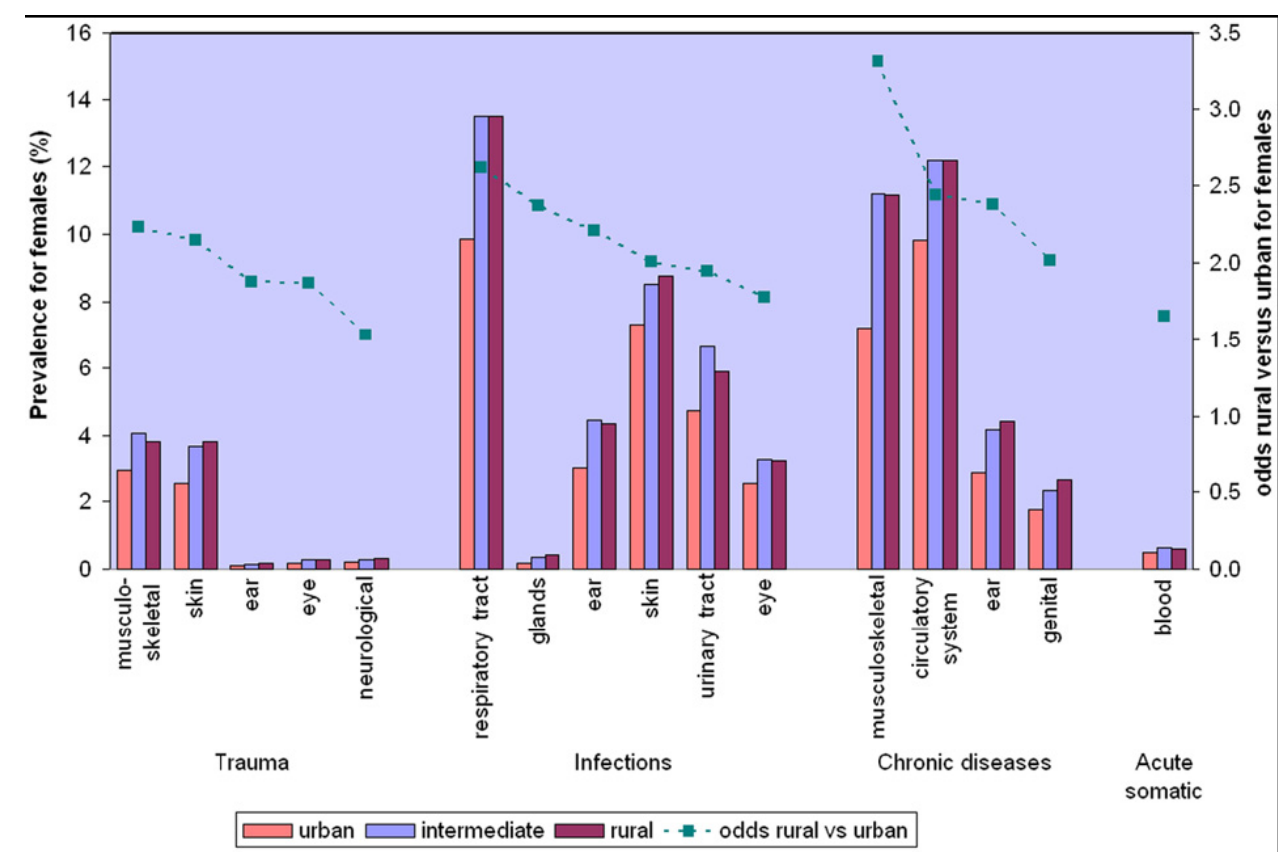


Kroneman, M., Verheij, R., Tacken, M., Zee, J. van der. Urban-rural health differences: primary care data and self reported data render different results. Health and Place: 2010

Table 2

Urban-rural differences in health problems presented to general practice and self-reported.

\begin{tabular}{|c|c|c|c|c|c|c|}
\hline & \multirow{2}{*}{$\begin{array}{l}\text { Odds ratio } \\
\text { rural/urban }\end{array}$} & \multicolumn{2}{|c|}{ 95\% Confidence interval } & \multicolumn{2}{|c|}{ Prevalence (\%) } & \multirow[t]{2}{*}{$\mathrm{ICC}^{\mathrm{c}}$} \\
\hline & & lower & upper & urban & rural & \\
\hline \multicolumn{7}{|l|}{ GP-recorded health problems ${ }^{\mathrm{a}}$} \\
\hline \multicolumn{7}{|l|}{ Males } \\
\hline Trauma & 3.31 & 1.70 & 6.45 & 6.1 & 10.7 & 0.25 \\
\hline Chronic diseases & 3.30 & 1.18 & 9.21 & 27.2 & 33.9 & 0.45 \\
\hline Acute somatic & 2.92 & 1.04 & 8.22 & 28.8 & 34.6 & 0.45 \\
\hline Infections & 2.91 & 1.18 & 7.18 & 19.5 & 25.2 & 0.38 \\
\hline Family planning & 2.53 & 1.66 & 3.88 & 0.2 & 0.6 & 0.07 \\
\hline Neoplasms & 1.65 & 1.01 & 2.68 & 2.5 & 3.0 & 0.15 \\
\hline \multicolumn{7}{|l|}{ Females } \\
\hline Chronic diseases & 3.54 & 1.17 & 10.77 & 34.4 & 42.0 & 0.49 \\
\hline Infections & 3.09 & 1.14 & 8.34 & 25.6 & 32.2 & 0.43 \\
\hline Trauma & 2.62 & 1.36 & 5.04 & 6.1 & 8.6 & 0.24 \\
\hline \multicolumn{7}{|l|}{ Self-reported health problems ${ }^{b}$} \\
\hline \multicolumn{7}{|l|}{ Males } \\
\hline Acute somatic problems & 0.60 & 0.42 & 0.85 & 85.1 & 78.3 & 0.04 \\
\hline Mental health problems & 0.63 & 0.49 & 0.81 & 45.2 & 39.5 & 0.01 \\
\hline Chronic health problems & n.s. & & & 51.8 & 47.6 & 0.01 \\
\hline Perceived general health ( $\%$ good) & n.s. & & & 77.2 & 80.3 & 0.01 \\
\hline \multicolumn{7}{|l|}{ Females } \\
\hline Acute somatic problems & 0.48 & 0.31 & 0.73 & 91.0 & 84.7 & 0.07 \\
\hline Mental health problems & 0.67 & 0.55 & 0.82 & 44.9 & 39.1 & 0.00 \\
\hline Chronic health problems & n.s. & & & 63.4 & 57.0 & 0.02 \\
\hline Perceived general health (\% good) & 1.52 & 1.18 & 1.98 & 72.7 & 80.2 & 0.02 \\
\hline
\end{tabular}

a Presented are significant odds ratios at level $p<0.05$; prevalence is age standardized.

${ }^{b}$ Acute complaints: $0=$ no complaints, $1=1$ or more acute complaints; $G H Q \geq 2: 0=$ no, $1=$ yes (possible psychiatric case); Chronic condition: $0=$ no chronic condition, $1=1$ or more chronic condition(s): Perceived general health: $0=$ mediocre or bad, $1=$ good, very good, excellent: Prevalence is age standardized.

'ICC = Intra-class correlation coefficient.

Table 3

Detailed urban-rural health differences presented to general practice ${ }^{\text {. }}$

\begin{tabular}{|c|c|c|c|c|c|c|}
\hline & \multirow{2}{*}{$\begin{array}{l}\text { Odds ratio } \\
\text { rural/urban }\end{array}$} & \multicolumn{2}{|l|}{$95 \% \mathrm{Cl}$} & \multicolumn{2}{|c|}{ Prevalence (\%) } & \multirow[t]{2}{*}{$\mathrm{ICC}^{\prime}$} \\
\hline & & Lower & upper & urban & rural & \\
\hline \multicolumn{7}{|l|}{ Males } \\
\hline Trauma: eye & 4.43 & 2.93 & 6.69 & 0.3 & 1.1 & 0.07 \\
\hline Trauma: skin & 2.81 & 1.64 & 4.81 & 2.6 & 4.9 & 0.17 \\
\hline Trauma: musculoskeletal & 2.69 & 1.59 & 4.54 & 2.7 & 4.5 & 0.17 \\
\hline Infections: respiratory tract & 2.42 & 1.20 & 4.86 & 7.7 & 10.6 & 0.27 \\
\hline Infections: ear & 2.30 & 1.41 & 3.77 & 2.9 & 4.4 & 0.15 \\
\hline Infections: skin & 1.93 & 1.02 & 3.66 & 6.7 & 7.9 & 0.23 \\
\hline Infections: glands & 1.85 & 1.09 & 3.13 & 0.2 & 0.3 & 0.09 \\
\hline Chronic disease: musculoskeletal & 3.38 & 1.84 & 6.24 & 4.5 & 8.4 & 0.22 \\
\hline Chronic disease: ear & 2.41 & 1.42 & 4.12 & 2.8 & 4.7 & 0.17 \\
\hline Chronic disease: metabolism & 1.95 & 1.11 & 3.42 & 2.4 & 2.9 & 0.19 \\
\hline Acute somatic: musculoskeletal & 2.40 & 1.10 & 5.42 & 15.2 & 16.0 & 0.33 \\
\hline Acute somatic: general & 1.67 & 1.01 & 2.75 & 2.4 & 3.1 & 0.15 \\
\hline Acute somatic: eye & 1.54 & 1.01 & 2.37 & 1.4 & 1.9 & 0.11 \\
\hline \multicolumn{7}{|l|}{ Females } \\
\hline Trauma: musculoskeletal & 2.23 & 1.31 & 3.79 & 3.0 & 3.8 & 0.17 \\
\hline Trauma: skin & 2.15 & 1.27 & 3.61 & 2.5 & 3.8 & 0.16 \\
\hline Trauma: ear & 1.88 & 1.12 & 3.16 & 0.1 & 0.2 & 0.05 \\
\hline Trauma: eye & 1.87 & 1.13 & 3.08 & 0.2 & 0.3 & 0.08 \\
\hline Trauma: neurological & 1.53 & 1.00 & 2.33 & 0.2 & 0.3 & 0.06 \\
\hline Infections: respiratory tract & 2.62 & 1.21 & 5.64 & 9.8 & 13.5 & 0.31 \\
\hline Infections: glands & 2.37 & 1.19 & 4.73 & 0.2 & 0.4 & 0.20 \\
\hline Infections: ear & 2.21 & 1.32 & 3.7 & 3.0 & 4.3 & 0.31 \\
\hline Infections: skin & 2.01 & 1.02 & 3.94 & 7.3 & 8.8 & 0.26 \\
\hline Infections: urinary tract & 1.95 & 1.05 & 3.64 & 4.7 & 5.9 & 0.22 \\
\hline Infections: eye & 1.71 & 1.07 & 2.75 & 2.5 & 3.2 & 0.14 \\
\hline Chronic disease: musculoskeletal & 3.31 & 1.62 & 6.79 & 7.21 & 11.17 & 0.28 \\
\hline Chronic disease: circulatory system & 2.44 & 1.11 & 5.37 & 9.82 & 12.17 & 0.32 \\
\hline Chronic disease: ear & 2.38 & 1.41 & 4.04 & 2.87 & 4.41 & 0.17 \\
\hline Chronic disease: genital & 2.02 & 1.25 & 3.26 & 1.78 & 2.67 & 0.14 \\
\hline Acute somatic: blood & 1.65 & 1.05 & 2.58 & 0.50 & 0.60 & 0.10 \\
\hline
\end{tabular}

a Presented are significant odds ratios at level $p<0.05$ : prevalence is age standardized.

b ICC = Intra-class correlation coefficient. 